\title{
The Effect of Intraventricular Blood on Cerebral Blood Flow in Newborn Dogs
}

\author{
DANIEL G. BATTON AND ELIZABETH E. NARDIS \\ Department of Pediatrics, Division of Neonatology, The Milton S. Hershey Medical Center, The Pennsylvania \\ State University, Hershey, Pennsylvania 17033
}

\begin{abstract}
We investigated the effect of intraventricular blood on cerebral blood flow in the newborn puppy by infusing autologous blood into the lateral ventricle to produce and maintain an intraventricular pressure of approximately $15 \mathrm{~mm} \mathrm{Hg}$ (mild insult), $30 \mathrm{~mm} \mathrm{Hg}$ (moderate insult), or $50 \mathrm{~mm} \mathrm{Hg}$ (severe insult) for $20 \mathrm{~min}$. As the intraventricular pressure increased, flow decreased progressively to all areas of the brain directly proportional to the cerebral perfusion pressure. On return of the intraventricular pressure to baseline level, cerebral blood flow normalized despite the continued presence of a large amount of blood within the lateral ventricles. We suggest that blood within the ventricular system can result in a significant acute reduction of cerebral blood flow which appears to be mediated through the effect on cerebral perfusion pressure. (Pediatr Res 21: 511-515, 1987)
\end{abstract}

\section{Abbreviations}

GM-IVH, germinal matrix-intraventricular hemorrhage CBF, cerebral blood flow

rCBF, regional cerebral blood flow

IVP, intraventricular pressure

CPP, cerebral perfusion pressure

GM-IVH occurs in $44-55 \%$ of newborns with a birth weight $\leq 1500 \mathrm{~g}(1,2)$. Although the hemorrhage is usually limited to the germinal matrix area or contained within the ventricular system, some $15-43 \%$ of infants with GM-IVH develop an associated intraparenchymal hemorrhage (1-3). Since this parenchymal lesion is associated with a high incidence of serious longterm neurological sequelae (4-8), understanding its pathogenesis is of extreme importance.

Although pathological studies have shown that most parenchymal hemorrhages result from ischemic infarction of the periventricular white matter, rather than rupture of the intraventricular hemorrhage (9), the origin of the ischemia responsible for this lesion is unknown. Volpe et al. (10) have theorized that ischemia may result from either systemic hypotension and loss of autoregulation of CBF or, secondarily, from the effects of blood within the ventricular system. Intraventricular blood could impair perfusion to this area either by compression of periventricular vessels due to ventricular distention or by producing vasospasm. Since little is known about this subject in the newborn, the purpose of this study was to investigate the effect of intraventricular blood on $\mathrm{rCBF}$ in the newborn dog.

Received August 21, 1986; accepted December 22, 1986.

Correspondence and requests for reprints Daniel G. Batton, M.D., Department of Pediatrics, Children's Hospital of The King's Daughters, Eastern Virginia Medical School, Norfolk, VA 23507.

\section{METHODS}

Animal preparation. Following light halothane anesthesia, newborn dogs, 3-10 days of age (mean age 6 days for all groups) were tracheostomized, paralyzed with subcutaneous pancuronium bromide, and ventilated with a mixture of $70 \%$ nitrous oxide and $30 \%$ oxygen using a Harvard small-animal ventilator. The ventilator rate and tidal volume were adjusted to maintain normal blood gases. A femoral artery was exposed and catheterized with a 30-gauge Teflon catheter to monitor blood pressure and blood gases. The other femoral artery and vein were catheterized for administration of $\left[{ }^{14} \mathrm{C}\right]$ iodoantipyrine and collection of blood samples during rCBF determination. Temperature was controlled by a rectal thermocouple and maintained at $37^{\circ}$ by a heat lamp. With the dog's skull in a stereotaxic frame, a small, longitudinal scalp incision was made over the sagittal suture after subcutaneous infiltration with procaine. The scalp and underlying periosteum were retracted to expose a $2-\mathrm{cm}$ area of the calvarium. A 1-mm burr hole was drilled through the calvarium in the right parasagittal area posterior to the coronal suture. A 20-gauge glass capillary tube with a stylet was then inserted through the burr hole and advanced until spinal fluid was obtained. The catheter was attached by a silastic rubber tubing to a T-piece, one arm of which was connected to a pressure transducer for recording of IVP and the other arm to a Harvard pump for the infusion of blood. Proper position of the intraventricular catheter was confirmed by observing appropriate cardiac and respiratory variations of the pressure waveform. The CPP was defined as the mean arterial blood pressure minus the intraventricular pressure. Through the arterial catheter, $6 \mathrm{ml} / \mathrm{kg}$ of blood were slowly withdrawn from all of the animals. This blood was subsequently infused through the intraventricular catheter in some of the puppies.

Experimental design. The first group of puppies served as controls and underwent the same surgical procedures (including the placement of an intraventricular catheter), blood withdrawal, and time course prior to determination of rCBF as the experimental animals (Fig. 1). In three groups of puppies, blood was infused through the intraventricular catheter at a varying rate to produce and maintain an intraventricular pressure of approximately $15 \mathrm{~mm} \mathrm{Hg}$ (mild insult), $30 \mathrm{~mm} \mathrm{Hg}$ (moderate insult), or $50 \mathrm{~mm} \mathrm{Hg}$ (severe insult) for $20 \mathrm{~min}$. At the end of the $20-$ min infusion $\mathrm{rCBF}$ was determined.

Two additional groups of dogs were studied. In one group, blood was infused into the lateral ventricle to produce and maintain an IVP of approximately $50 \mathrm{~mm} \mathrm{Hg}$ for $20 \mathrm{~min}$ as described above. The infusion was then discontinued and the IVP allowed to return to the baseline level at which time rCBF was measured. In the final group of puppies, normal saline was infused into the lateral ventricle to produce and maintain an IVP of approximately $50 \mathrm{~mm} \mathrm{Hg}$ for $20 \mathrm{~min}$ and rCBF was measured at the end of the infusion. 
$\mathrm{CBF}$ was measured by means of the autoradiographic technique employing $\left[{ }^{14} \mathrm{C}\right]$ iodoantipyrine as the inert tracer (11). Fifty $\mu \mathrm{Ci}$ of $\left[{ }^{14} \mathrm{C}\right]$ iodoantipyrine were infused into the inferior vena cava at a constant rate over $60 \mathrm{~s}$, while drops of femoral arterial blood were collected at 5-s intervals. When the infusion was completed, the circulation was stopped by a bolus administration of $\mathrm{KCl}$ through the femoral venous catheter. The brain was removed and frozen in Freon 12 at $-30^{\circ} \mathrm{C}$. Sections of brain, $50-\mu$ thick, were cut in a cryostat, placed on glass slides, dried, and applied to single emulsion mammography film. After the autoradiograms were developed, rCBF was determined from readings of the optical densities as compared to known standards.

Control and experimental data were compared using analysis of variance, linear regression analysis, paired Student's $t$ test, and unpaired Student's $t$ test with the Bonferoni correction for multiple comparisons.

\section{RESULTS}

Postmortem examination confirmed the proper location of the intraventricular catheter in all puppies. In the animals undergoing blood infusion, blood was present throughout the frontal and occipital horns of the lateral ventricles bilaterally, while a lesser amount of blood was seen in the third ventricle. The ventricles appeared more dilated in the puppies with the highest IVP and no parenchymal blood was present in any of the animals. In the puppies undergoing normal saline infusion, the lateral ventricles were also significantly dilated bilaterally.

The physiological data at the time of rCBF determination for the first four groups of dogs are listed in Table 1. The IVP was 4 $\pm 2 \mathrm{~mm} \mathrm{Hg}$ (mean $\pm \mathrm{SD}$ ) for the control group and $15 \pm 1,31$ \pm 2 , and $52 \pm 3 \mathrm{~mm} \mathrm{Hg}$ for the mild, moderate, and severe insult groups, respectively, and these values were directly proportional to the volume of blood infused (Fig. 2). There were no differences in blood pressure, hematocrit, or arterial blood gases

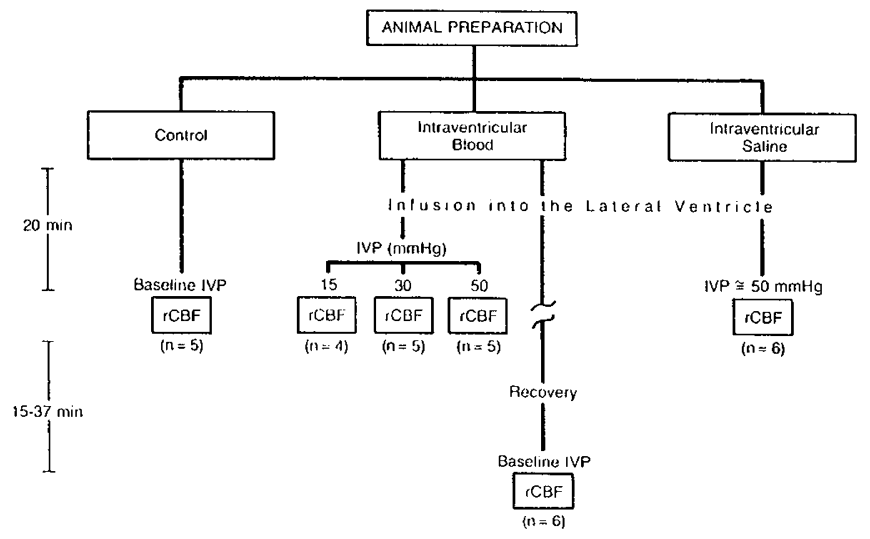

Fig. 1. Experimental design. between control and experimental animals. The cerebral perfusion pressure decreased from $66 \pm 10 \mathrm{~mm} \mathrm{Hg}$ in the control group to $18 \pm 10 \mathrm{~mm} \mathrm{Hg}$ in the severe insult group $(p<0.001$, Table 1).

Regional CBF values for the control animals were within the range which have previously been reported for newborn dogs using the same technique (Table 2) (12-14). The pattern of moderate flow to the cortex, high flow to the central gray matter and brain stem, and low flow to the white matter has been described previously (12-14). There were no significant differences in flow to either side of the brain in control or experimental puppies. Regional CBF decreased significantly throughout the brain in the experimental animals as compared to controls (Table 2). These changes were most marked in the severe insult group and lowest absolute flows occurred in the white matter. Regional CBF was linearly related to CPP for all areas of the brain and four representative areas are shown in Figure 3.

The control animals were compared with the two groups of animals undergoing infusion of blood to the highest IVP (i.e. 50 $\mathrm{mm} \mathrm{Hg}$ ) and to the group in which normal saline was infused. The volume of normal saline required to maintain an IVP of 50 $\mathrm{mm} \mathrm{Hg}$ was significantly greater than the volume of blood required $(7.6 \pm 1.1$ versus $4.1 \pm 0.4 \mathrm{ml} / \mathrm{kg})$. The physiological data following animal preparation (baseline) and at the time of rCBF determination are given in Table 3. There were no significant differences in the arterial blood gases at the time of $\mathrm{rCBF}$ determination between the four groups, although the $\mathrm{PaCO}_{2}$ tended to decrease during normal saline infusion. Heart rate and systemic blood pressure significantly increased following normal saline infusion, whereas these parameters did not change with blood infusion.

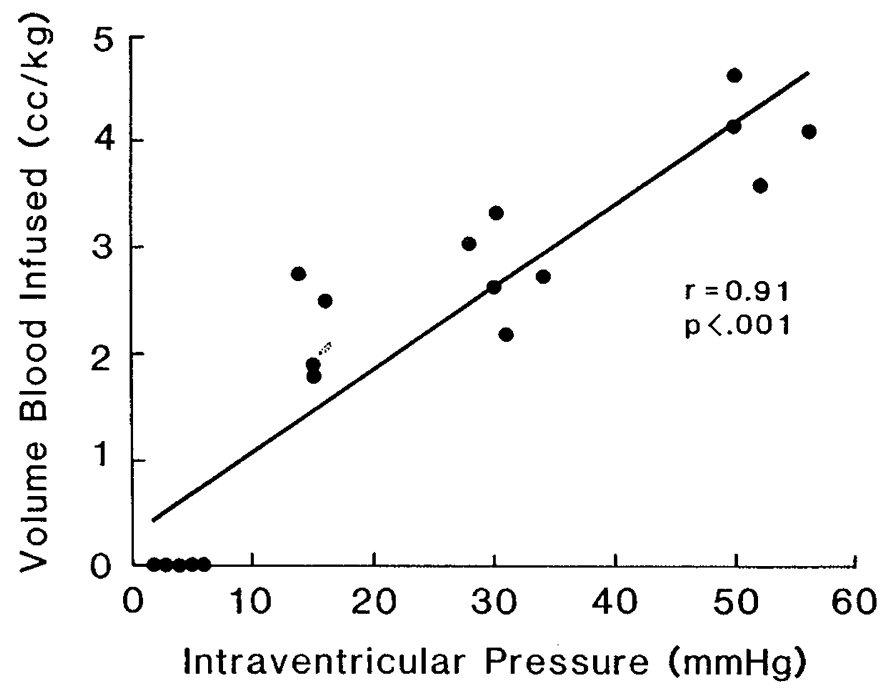

Fig. 2. Linear regression analysis of the volume of blood infused into the lateral ventricle and the intraventricular pressure $y=0.8 x+0.27$.

Table 1. Physiological data following infusion of blood into lateral ventricle of newborn dogs*

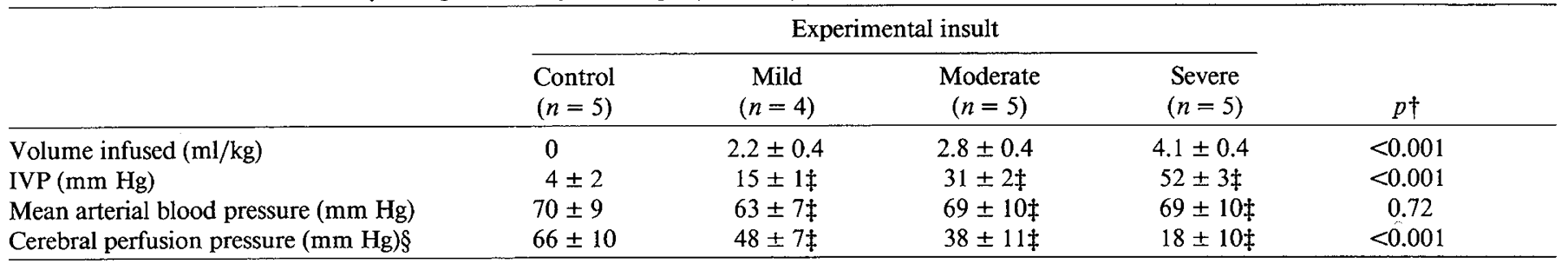

$*$ Values are mean $\pm \mathrm{SD}$.

$\dagger$ Analysis of variance of all four groups.

$\ddagger p<0.02$ compared with control by unpaired Student's $t$ test and the Bonferoni correction.

$\S$ Mean arterial blood pressure minus intraventricular pressure. 
Table 2. $r C B F$ following infusion of blood into lateral ventricle of newborn dogs*

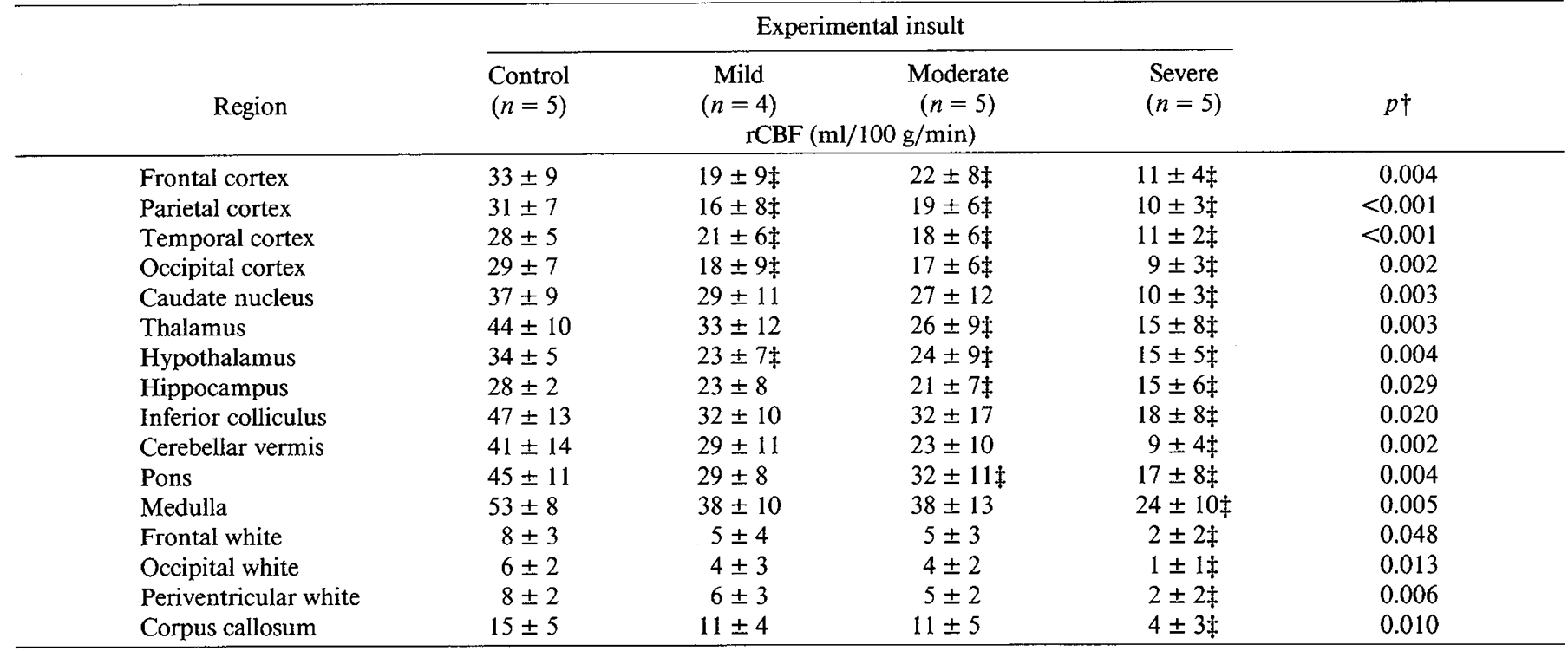

* All data given as mean $\pm \mathrm{SD}$.

$\dagger$ Analysis of variance of all four groups.

$\ddagger p<0.02$ compared with control by unpaired Student's $t$ test and the Bonferoni correction.
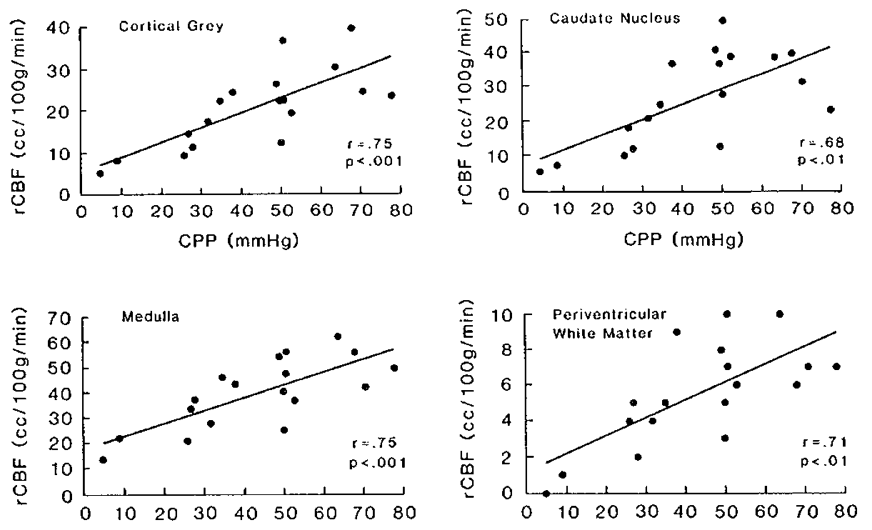

$\mathrm{CPP}(\mathrm{mmHg})$

$\mathrm{CPP}(\mathrm{mmHg})$

Fig. 3. Linear regression analysis of $\mathrm{rCBF}$ and CPP. Cortical gray y $=0.35 \mathrm{x}+5.1 ;$ caudate nucleus $\mathrm{y}=0.46 \mathrm{x}+6.7$; medulla $\mathrm{y}=0.50 \mathrm{x}+$ 18 ; periventricular white matter $\mathrm{y}=0.10 \mathrm{x}+1.1$.

The generalized acute decrease in rCBF following infusion of blood into the lateral ventricle was no longer evident once the IVP had returned to the baseline level (Table 4). Regional CBF values for the animals undergoing normal saline infusion were no different from control values except for the pons and medulla where flow was higher.

\section{DISCUSSION}

Volpe et al. (10) have suggested one of the possible causes for the ischemic insult responsible for hemorrhagic intraparenchymal infarction in premature infants may be the secondary effect of blood within the lateral ventricle on CBF. The frequent association of an ipsilateral IVH with this intraparenchymal lesion supports this hypothesis (4). Our results provide further evidence that blood within the ventricular system can compromise cerebral perfusion.

However, it is not known whether or not the decrease in CBF we observed in these acute experiments is sufficient to produce pathological ischemic damage. Karlowicz et al. (15) have meas- ured CBF in newborn lambs 6 days following the infusion of blood into the lateral ventricle and have noted no difference in flow to the cerebral hemisphere undergoing intraventricular infusion as compared with the contralateral hemisphere. Although no control animals were studied, it appeared that intraventricular blood did not lead to a long-term derangement of CBF. Goske et al. (16) injected blood into the ventricles of newborn sheep and observed these animals clinically for $3 \mathrm{wk}$ following the insult. They found that animals injected with less than $0.58 \mathrm{ml} /$ $\mathrm{kg}$ of blood tolerated the procedure well and did not develop neurological sequelae. However, two of the three animals receiving more than $1.6 \mathrm{ml} / \mathrm{kg}$ of blood into the ventricle subsequently showed neurological symptoms. Since these animals became hypotensive and bradycardic following the intraventricular infusion, it is not clear whether the neurological sequelae were due to the effect of blood within the ventricle or related to the systemic effects of the insult. Although we have demonstrated an acute effect of intraventricular blood on CBF, there is insufficient data to conclude that this can result in parenchymal ischemic necrosis.

The mechanism by which intraventricular blood may compromise CBF has not been delineated. Volpe et al. (10) suggested this effect may be due to vasospasm of the middle cerebral artery or to compression of periventricular vessels. Adult patients suffering a subarachnoid hemorrhage are known to be at risk for the development of secondary cerebral ischemia due to arterial vasospasm, but this usually occurs a few days following the initial insult rather than acutely (17). Since CBF returned to control values in our study on normalization of the IVP despite persistence of blood within the ventricular system, it seems unlikely that this transient decrease in CBF was mediated by vasospasm. It is perhaps more likely that the effect we observed was secondary to compression of periventricular vessels since CBF seemed to be primarily influenced by the magnitude of the IVP elevation and compromise in cerebral perfusion pressure. The lack of a compensatory increase in systemic blood pressure (i.e. Cushing's response) following elevation of the IVP has been observed by others. Simon and Bayne (18) have shown that marked intracranial hypertension in sheep does not result in elevation of the systemic blood pressure until the intracranial pressure approximates the mean arterial blood pressure. This may explain why systemic blood pressure did not increase in our study since the IVP remained lower than the mean arterial blood pressure. 
Table 3. Physiological data for control animals and for animals undergoing infusion to IVP of approximately $50 \mathrm{~mm}$ Hg*

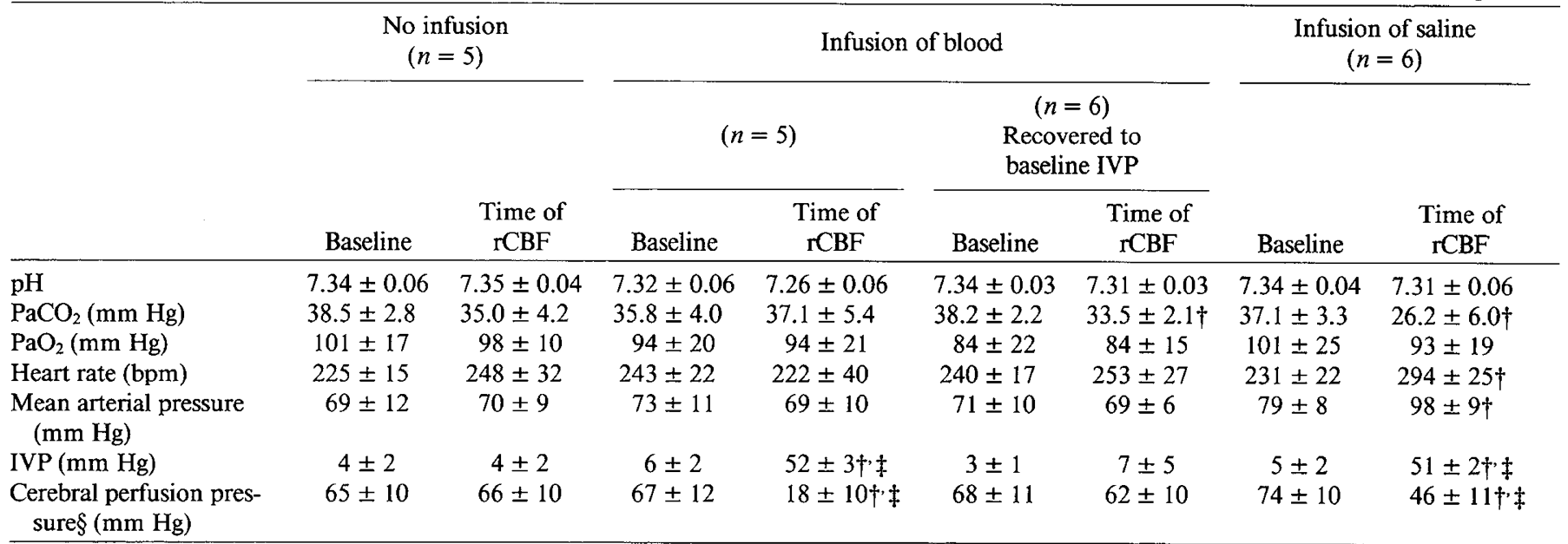

$*$ All data given as mean $\pm \mathrm{SD}$.

$\dagger p<0.05$ compared with baseline by paired Student's $t$ test.

$\ddagger p<0.02$ compared with control animals at the time of rCBF determination using unpaired Student's $t$ test and the Bonferoni correction.

$\S$ Mean arterial blood pressure minus IVP.

Table 4. $r C B F$ data for control animals and for animals undergoing infusion to IVP of approximately $50 \mathrm{~mm} \mathrm{Hg}$

\begin{tabular}{|c|c|c|c|c|}
\hline & \multicolumn{3}{|c|}{ Infusion of blood } & \multirow[b]{2}{*}{$\begin{array}{l}\text { Infusion of saline } \\
\qquad(n=6)\end{array}$} \\
\hline & $\begin{array}{l}\text { Control } \\
(n=5)\end{array}$ & $(n=5)$ & $\begin{array}{c}(n=6) \\
\text { Recovered } \\
\text { to baseline IVP } \\
0 \mathrm{~g} / \mathrm{min})\end{array}$ & \\
\hline $\begin{array}{l}\text { Gray matter } \\
\text { Frontal cortex } \\
\text { Parietal cortex } \\
\text { Temporal cortex } \\
\text { Occipital cortex } \\
\text { Cortical gray } \\
\text { Caudate nucleus } \\
\text { Thalamus } \\
\text { Hypothalamus } \\
\text { Hippocampus } \\
\text { Inferior colliculi } \\
\text { Cerebellar vermis } \\
\text { Pons } \\
\text { Medulla }\end{array}$ & $\begin{array}{l}33 \pm 9 \\
31 \pm 8 \\
28 \pm 6 \\
29 \pm 7 \\
31 \pm 8 \\
37 \pm 10 \\
44 \pm 11 \\
34 \pm 6 \\
28 \pm 2 \\
47 \pm 13 \\
41 \pm 4 \\
45 \pm 11 \\
53 \pm 8\end{array}$ & $\begin{aligned} & 11 \pm 4 \dagger \\
& 10 \pm 3 \ddagger \\
& 11 \pm 2 \ddagger \\
& 9 \pm 3 \ddagger \\
& 10 \pm 3 \ddagger \\
& 10 \pm 5 \ddagger \\
& 15 \pm 8 \dagger \\
& 15 \pm 5 \dagger \\
& 15 \pm 6 \dagger \\
& 18 \pm 8 \dagger \\
& 9 \pm 4 \dagger \\
& 17 \pm 8 \dagger \\
& 24 \pm 10 \dagger\end{aligned}$ & $\begin{array}{l}42 \pm 9 \\
40 \pm 13 \\
36 \pm 6 \\
32 \pm 5 \\
37 \pm 9 \\
45 \pm 8 \\
55 \pm 11 \\
33 \pm 12 \\
37 \pm 7 \\
56 \pm 15 \\
44 \pm 9 \\
45 \pm 11 \\
50 \pm 14\end{array}$ & $\begin{array}{l}32 \pm 5 \\
29 \pm 7 \\
30 \pm 16 \\
30 \pm 12 \\
30 \pm 10 \\
35 \pm 12 \\
61 \pm 29 \\
60 \pm 20 \\
46 \pm 32 \\
70 \pm 16 \\
53 \pm 15 \\
75 \pm 17 \dagger \\
84 \pm 19 \dagger\end{array}$ \\
\hline $\begin{array}{l}\text { White matter } \\
\text { Frontal } \\
\text { Occipital } \\
\text { Corpus callosum } \\
\text { Periventricular }\end{array}$ & $\begin{array}{r}8 \pm 3 \\
6 \pm 2 \\
15 \pm 5 \\
8 \pm 2\end{array}$ & $\begin{array}{l}2 \pm 2 \S \\
1 \pm 1 \dagger \\
4 \pm 3 \dagger \\
2 \pm 2 \dagger\end{array}$ & $\begin{aligned} 8 & \pm 2 \\
6 & \pm 1 \\
14 & \pm 4 \\
8 & \pm 1\end{aligned}$ & $\begin{array}{r}8 \pm 3 \\
6 \pm 3 \\
15 \pm 4 \\
8 \pm 3\end{array}$ \\
\hline
\end{tabular}

* All data given as mean \pm SD. Statistical analysis by unpaired Student's $t$ test with Bonferoni correction.

$\dagger p<0.01$ compared to control.

$\ddagger p<0.001$ compared to control.

$\S p<0.02$ compared to control.

Loss of autoregulation of $\mathrm{CBF}$ and concomitant systemic hypotension have been considered important predisposing factors to the development of cerebral ischemia in human newborns suffering from respiratory distress and perinatal asphyxia (19). Autoregulation in nondistressed human newborns has not been well studied, but Hernandez et al. (20) have demonstrated intact autoregulation in healthy newborns dogs. In this study, CBF remained constant when systemic arterial pressure was altered from 27 to $97 \mathrm{~mm} \mathrm{Hg}$. Although the intracranial pressure was not measured, it presumably did not change. The autoregulation of CBF, despite marked fluctuations of cerebral perfusion pres- sures, suggests compensatory alterations in cerebral vascular resistance. In our study, cerebral perfusion pressure was altered by elevating IVP rather than by changing systemic blood pressure. Under these conditions, physical compression of blood vessels may have limited the vasodilatory response. Consequently, the only compensatory mechanism remaining to maintain CBF is an increase in systemic blood pressure which did not occur in the blood-infused animals.

The animals undergoing normal saline infusion had CBF values similar to control animals despite marked elevation of the IVP. In these animals, systemic blood pressure increased $24 \%$ 
following saline infusion. This increase in blood pressure lessened the drop in CPP which would have occurred if blood pressure had remained unchanged as in the blood-infused dogs. Presumably CBF was maintained in the saline-infused animals because cerebral vascular resistance decreased sufficiently to compensate for the decrease in CPP.

In summary, we have shown that the infusion of blood into the lateral ventricle of the newborn dog can have a profound generalized effect on CBF. This effect occurs acutely and appears to be related to a decrease in cerebral perfusion pressure. The data are consistent with the hypothesis that an intraventricular hemorrhage may result in parenchymal ischemia. However, further work will be required to firmly establish the validity of this association.

Acknowledgments. The authors thank Dr. M. Jeffrey Maisels for his review of the manuscript, Dr. Jonathan Hellman for his technical assistance, and Dr. Charles Antle for his help with statistical analyses.

\section{REFERENCES}

1. Papile L, Burstein J, Burstein R, Koffler H 1978 The incidence and evolution of subependymal and intraventricular hemorrhage. A study of infants with birthweight less than 1500 grams. J Pediatr 92:529-534

2. Partridge JC, Babcock DS, Steichen JJ, Han BK 1983 Optimal timing for diagnostic cranial ultrasound in low birthweight infants: detection of intracranial hemorrhage and ventricular dilatation. J Pediatr 102:281-287

3. Shinnar S, Molteni RA, Gammon K, D'Souza BJ, Altman J, Freeman JM 1982 Intraventricular hemorrhage in the premature infant. A changing outlook. N Engl J Med 306:1464-1468

4. McMenamin JB, Shackleford GD, Volpe JJ 1984 Outcome of neonatal intraventricular hemorrhage with periventricular echodense lesions. Ann Neurol $15: 285-290$

5. Palmer P, Dubowitz LMS, Levene MI, Dubowitz V 1982 Developmental and neurological progress of preterm infants with intraventricular hemorrhage and ventricular dilatation. Arch Dis Child 57:748-753
6. Papile L, Munsick-Bruno G, Schaefer A 1983 Relationship of cerebral intraventricular hemorrhage and early childhood neurological handicaps. J Pediatr 103:273-277

7. Stewart AL, Thornburn RJ, Hope PL, Goldsmith M, Lipscomb AP Reynolds EOR 1983 Ultrasound appearance of the brain in very preterm infants and neurodevelopmental outcome at 18 months of age. Arch Dis Child 58:598604

8. Williamson WD, Desmond MM, Wilson GS, Murphy MA, Rozelle J, GarciaPrats JA 1983 Survival of low birthweight infants with neonatal intraventricular hemorrhage. Am J Dis Child 137:1181-1184

9. Flodmark O, Becker LE, Harwood-Nash DC, Fitzhardinge PM, Fitz CR, Chuang SH 1980 Correlation between computed tomography and autopsy in premature and full-term neonates that have suffered perinatal asphyxia. Radiology 137:93-103

10. Volpe JJ, Herscovich P, Perlman JM, Raichle ME 1983 Positron emission tomography in the newborn. Extensive impairment of regional cerebral blood flow with intraventricular hemorrhage and hemorrhagic intracerebral involvement. Pediatrics 72:589-601

11. Sakurada O, Kennedy C, Jehle J, Brown JD, Carbin GL, Sokoloff L 1978 Measurement of local cerebral blood flow with ido $\left[{ }^{14} \mathrm{C}\right]$ antipyrine. Am $\mathbf{J}$ Physiol 234:H59-H66

12. Batton DG, Hellman J, Hernandez MJ, Maisels MJ 1983 Regional cerebral blood flow, cerebral blood velocity, and pulsatility index in newborn dogs. Pediatr Res 17:908-912

13. Cavazzuti M, Duffy TE 1982 Regulation of local cerebral blood flow in normal and hypoxic newborn dogs. Ann Neurol 11:247-257

14. Young RSK, Hernandez MJ, Yagel SK 1982 Selective reduction of blood flow to white matter during hypotension in newborn dogs: a possible mechanism of periventricular leukomalacia. Ann Neurol 12:445-448

15. Karlowicz RC, Koehler RC, Traystman RJ, Jones MD Jr 1984 The effect of intraventricular blood upon regional cerebral blood flow in the newborn lamb. Pediatr 18:1398A

16. Goske MJ, Morin FC, Eskin TA 1985 Experimental neonatal intraventricular hemorrhage: clinical, radiographic, and pathologic features. AJR 143:693

17. Heros RC, Zervas NT, Varsos V 1983 Cerebral vasospasm after subarachnoid hemorrhage: an update. Ann Neurol 14:599-608

18. Simon RP, Bayne LL 1984 Pulmonary lymphatic flow alterations during intracranial hypertension in sheep. Ann Neurol 15:188-194

19. Lou HC, Lassen NA, Friis-Hansen B 1979 Impaired autoregulation of cerebral blood flow in distressed newborn infants. $J$ Pediatr 94:118-121

20. Hernandez MJ, Brennan RW, Bowman GS 1980 Autoregulation of cerebral blood flow in the newborn dog. Brain Res 184:199-202 